\title{
Integration of CFD Methods into Concurrent Design of Internal Combustion Engine
}

\begin{abstract}
M. Polášek, J. Macek, O. Vítek, K. Kozel
This paper describes patterns of algorithms for different innovative levels of design at parametric, configuration and conceptual levels. They can be applied to Computer-aided Engine Design (CED). Data structures, process simulation hierarchy, engine simulation modules and the requirements for further development are described. An example of advanced thermodynamics modeling of combustion engines is included.
\end{abstract}

Keywords: Internal combustion engine, simulation, CAD, CFD, combustion, knock.

\section{Introduction}

Concurrent engineering technologies provide essential tools for acceleration of time-to-market procedures in automotive industry. Reciprocating engines could be a prime mover in future decades if all theoretically promising improvements are evaluated, tested and quickly realized after passing through the selection procedures. The huge amount of simulation codes in the field of Computational Fluid Dynamics, experimental tools and the data-processing capacities of contemporary computers on the one hand, and human inventive capacities on the other, call for their application in the thermodynamic design of contemporary engines.

The use of a virtual engine during the design phase is nowadays essential. This is due to both the new demands on efficiency and emission levels (including carbon dioxide levels) and the new possibilities in engine fuelling and combustion management together with the downsizing of engines thanks to super/turbocharging.

The current situation calls for changes not only due to great flexibility of control but also due to the new actuating concepts, e.g., in common rail injection, valve actuation, boost pressure control, etc. This should be reflected in the early design phase, giving an opportunity to predict new possibilities not only to provide a perfect simulation of the standard state usable in parametric design but also to incorporate new concepts.

This paper summarizes the possibilities and achievements in spark ignited (SI) turbocharged engine design. Engine models employed up to now, their hierarchical structure and the philosophy of the use of previous experience are described. A modular system of general thermodynamic elements usable for all types of volumetric engines (reciprocating, rotating, etc.) based on a finite volume approach has already been described [1, 2, 3]. Using these tools, real limits for high-b.m.e.p., downsized SI engines and optimized cycle parameters can be estimated in advance, taking into account the auto-ignition and knock limits. It is especially worthwhile to estimate an appropriate compression ratio that cannot be changed simply in a wide range after the engine structure is manufactured. The application of advanced models to the simulation of new combustion concepts is also discussed.
The purpose of the paper is to show the different level model use in the concurrent procedures. Therefore, a brief description is given of the applied methods and the results of simulations.

\section{Concept of computer aided concurrent design of an IC engine}

Engineering computational models can be classified according to the depth of reality description. This reflects the detail of reality description, namely whether both space and time are treated continuously, or one of them only discretely [4]. A distinction can be made between computational models on the deep level, medium level and shallow level. The deep level considers both space and time as continuous (partial differential equations (PDE) are used). The medium level usually considers space as discrete and time as continuous (ordinary differential equations (ODE) or differential-algebraic equations (DAE) are used). The other possibility of continuous space and discrete time is also used, but less frequently. The shallow level considers both space and time discretely (nonlinear algebraic equations are generally used) (Fig. 1).

The initial model is usually at the deep level. The medium level is a simplification of the deep level obtained by describing of the whole space or time area (interval) by a single variable. The shallow level is simplified by a further step where not only space (time) but also time (space) is described by a single variable. This means that the created object is considered as a chain of discrete events in discrete space and time. Certainly there exists a mixture of these models where different elements of different system levels are described by different kinds of models.

The primary reasons for simplifying of computational models is to accelerate simulation of the product behavior. The other purpose is to provide the inversion of the models on the shallow level, which is usually impossible or possible only with great difficulty on the medium or deep level. The inversion of models [3] is necessary for the application of the principle of successive approximations as the basic solving principle of the fundamental paradox of system theory - for details see [4]. 


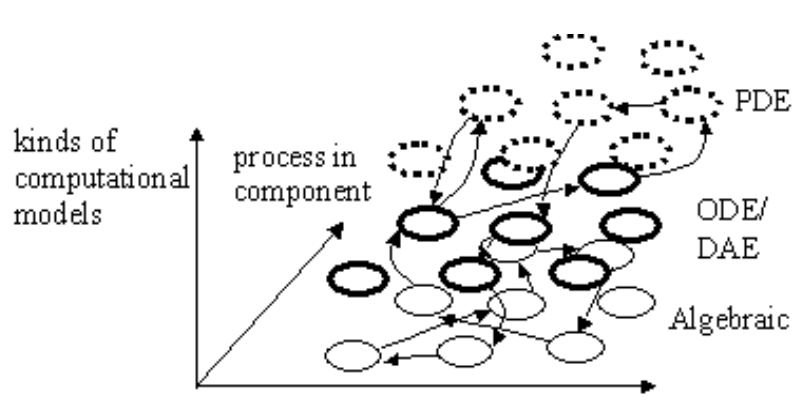

hier archy of components

Fig. 1: Trace of the design process through design procedures

The list of necessary engine sub-models is shown in the following table.

\begin{tabular}{|l|c|c|c|c|}
\hline \multicolumn{1}{|c|}{ Level of Model } & AE & ODE & DAE & PDE \\
\hline $\begin{array}{l}\text { Thermodynamic model in the } \\
\text { standard 0-D or 1-D version }\end{array}$ & & $\mathrm{X}$ & & $\mathrm{X}$ \\
\hline $\begin{array}{l}\text { Thermodynamic model } \\
\text { decomposed to processes in } \\
\text { engine cycle parts (see exam- } \\
\text { ples in the next section) }\end{array}$ & $\mathrm{X}$ & & $\mathrm{X}$ \\
\hline $\begin{array}{l}\text { Thermoaerodynamic 2.5-D } \\
\text { model suitable for new engine } \\
\text { lay-outs }\end{array}$ & & $\mathrm{X}$ & $\mathrm{X}$ \\
\hline $\begin{array}{l}\text { Fuel properties evaluation } \\
\text { (especially for gas mixtures) }\end{array}$ & & $\mathrm{X}$ & \\
\hline Fuel spray model & $\mathrm{X}$ & & $\mathrm{X}$ \\
\hline $\begin{array}{l}\text { Aerodynamic simulation of } \\
\text { valves and ports }\end{array}$ & & & \\
\hline $\begin{array}{l}\text { Aerodynamic simulation of } \\
\text { exhaust gas aftertreatment } \\
\text { systems (catalysts, soot filters) }\end{array}$ & & & \\
\hline $\begin{array}{l}\text { Radial centripetal } \\
\text { turbocharger turbine } \\
\text { simulation }\end{array}$ & $\mathrm{X}$ & \\
\hline $\begin{array}{l}\text { Gas mixing devices simulation } \\
\text { cylinder liners, valves, crank- } \\
\text { gasket), connecting rods and } \\
\text { crankshafts, etc. } \\
\text { thermal load simulation }\end{array}$ & $\mathrm{X}$ & & \\
\hline $\begin{array}{l}\text { Boundary conditions of } \\
\text { thermal load evaluation }\end{array}$ & & & \\
\hline $\begin{array}{l}\text { FEM static analysis applied to } \\
\text { aistons, piston rings, heads, }\end{array}$ & & & \\
\hline
\end{tabular}

Models of different levels (AE, ODE, etc.) are used either simultaneously or uniformly. The first approximation after the engine configuration is set provisionally, and is based mostly on AE methods (if these methods are missing a simple regression formula is used interpolating between the most similar design cases already analyzed). For the next turns of iteration, more profound methods are used. PDE methods are not mature in some cases for these aims. This concerns especially CFD models and also some complicated solid continuum dynamics. The reasons lie in the insufficient result of a trade-off between CPU time, the number of inputs needed (e.g., a very detailed description of the geometry is not available in the starting phase of engine design) and reliability - precision of results. On the other hand, top level methods should be used even for parameter estimation in the case of high boost pressures, where no experience is available. The results naturally influence the demands on engine motor-management. If a conflict of targets occurs, the initially estimated nominal power has to be changed.

Some examples of the formulation of SI-focused sub-models and their significance for engine optimization will be presented in the following text. Further, the application of CFD models in the design of the IC engine is demonstrated on a simulation of an unconventional cycle.

\section{Application of a thermodynamic model to SI engine downsizing concept simulation}

The current trend toward significant $\mathrm{CO}_{2}$ reduction calls for an increase in the fuel economy of engines and cars. In the case of passenger cars, there is permanent competition between SI engines and DI diesel engines. Before the two concepts converge, both have to be further optimized to fully utilize all potentials. The future of the conventional SI engine is the downsizing concept. It brings in a highly turbocharged small displacement engine. It is obvious that this causes new problems of higher mechanical and thermal stresses, knocking, turbocharger control, etc. The problems of downsized SI engine boost pressure optimization can be summarized as follows:

1. Boost pressure at a certain speed is primarily given by the required torque.

2. The high engine load causes higher temperature of the walls, as well as higher temperature of the cylinder charge.

3. Knocking combustion may occur at high temperature and pressure. This has to be avoided. Knocking considerably limits the parameters of SI engines. It is usually necessary to find a compromise among the used fuel knock rating/engine compression ratio/spark advance/boost pressure to operate the engine at knock limits to gain as high engine efficiency as possible.

4. Knock can be eliminated by delaying combustion or by decreasing the compression ratio. Both of these changes significantly deteriorate efficiency.

5. Boost pressure (or required torque) should be checked against the engine efficiency gain of a downsized engine.

Knock simulation is probably the most crucial problem of turbocharged SI engine simulations. Knock prediction is an important point in basic decisions on target parameters in SI engine development.

A quasi-dimensional model (Q-D or 0-D) was used for the engine parameter set-up in the first stage. In fact, the model 
stands at the second stage of the original model hierarchy, but it represents a very conventional and easy-to-use approach to simulation of the engine cycle. Experimental data and current knowledge can be used to calibrate the model. Therefore, it is not necessary to employ a shallow model for a preliminary determination of the engine parameters. Instead, the quasi-dimensional model is quite complex as regards the extent to which the engine lay-out is described see Fig. 2. The model enables us to simulate an SI engine including turbocharger, crank mechanism, etc. The obvious limitation of the Q-D model is the discrete treatment of all parts (pipes), which does not account for the fluid dynamics phenomena.

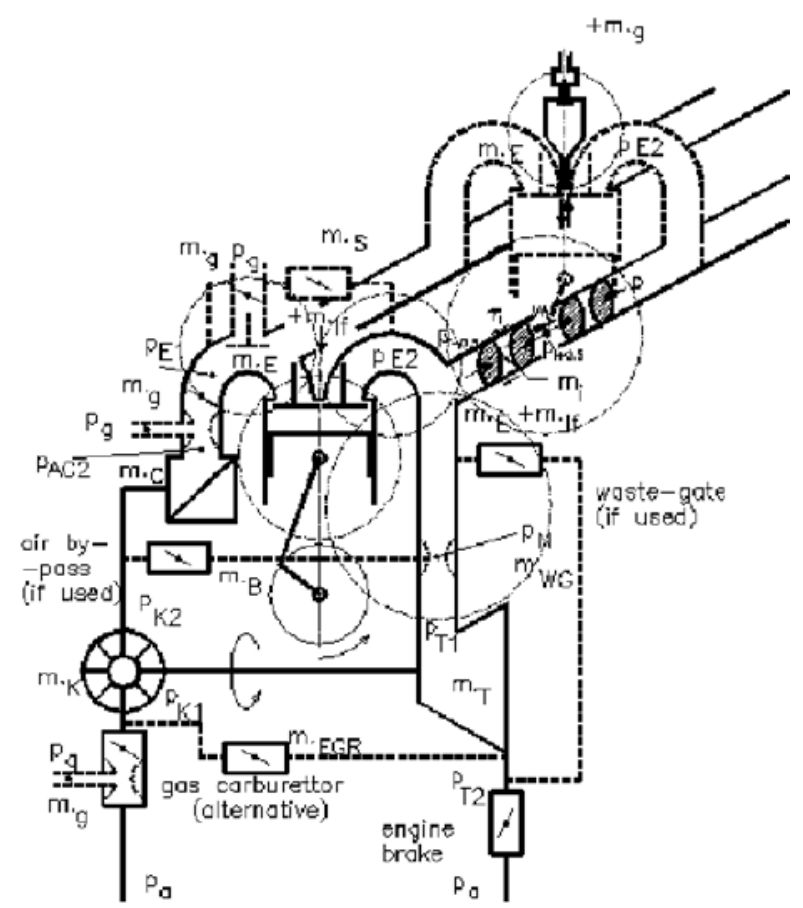

Fig. 2: Layout of a standard 1-D engine model

The procedure for using a different level model is described on the example of turbocharged SI engine optimizations. In the procedure presented here, three major levels of simulation are employed in an integrated procedure. The hierarchy is demonstrated in the following table.

This work uses a decoupled simulation of the engine cycle by means of the OBEH code and the knock properties of a fuel (KNOCK code. Describing knock in an SI engine, we usually consider self-ignition of unburned gas at a late stage of combustion. The phenomenon is often called end-gas knock. The end-gas knock is determined mainly by the temperature of the unburned mixture, which is pre-heated and compressed by the propagating flame and is cooled by the heat transfer to the cooling system via the cylinder walls. There- fore, it is necessary to formulate a zone model enabling a description of the unburned mixture, the reaction zone and the burned mixture. This is usually done using a Q-D approach introducing several zones describing the pertinent region in the combustion chamber. Each of the zones represents an open thermodynamic system to be described by conservation laws.

The temperature of the unburned mixture can be used to estimate the occurrence of knock. This procedure uses the assumption of a critical amount of products, i.e., free radicals, to be prepared to induce self-ignition. In a perfectly stirred reactor with constant pressure and temperature, the time to self-ignition induction can be estimated using the Guldberg-Waage-Arrhenius law for a particular fuel:

$$
\tau=A \cdot p^{-n} \cdot \exp \left(\frac{B}{T}\right)
$$

$\tau$ defines ignition delay, constants $A, B$ and exponent $n$ depend on the fuel under consideration. In fact, the reaction mechanism describing oxidation of a fuel is usually very complicated, and the solution is demanding. Equation (1) simplifies the procedure for a global description of all undergoing reactions. The ignition delay time itself is not sufficient for knock prediction, as both the temperature and the pressure in the cylinder of an engine change rapidly. The history of the states, i.e., the temperature and pressure that unburned mixture is exposed to, has to be taken into account. This can be done using an empirical assumption of transport and conservation of "readiness" of the mixture for self-ignition [5]. Hence, the instant of knock is estimated as follows:

$$
\int_{t=0}^{t_{i}} \frac{\mathrm{d} t}{\tau}=1 .
$$

The integration starts at the beginning of compression, and integration limit $t_{i}$ identifies the time of knock. There are two possibilities for determining induction time $\tau$ - use of the empirical reaction time correlation or that of the chemical mechanisms describing the full oxidation process of a fuel [6]. In the work presented here, an empirical correlation for the induction time proposed in [7] has been used to describe the fuel behavior. The authors further employed a chemical kinetics solution to describe the induction time of isooctane and methane. The model has been combined in decoupled way with the OBEH cycle, as this provides us with the parameters of the knock sub-model. The results of the chemical kinetics computations and a comparison with data obtained by the empirical correlation are shown in Fig. 3. The figure shows that the empirical correlation provides a good description of the ignition delay time in the region between high and low temperature ignition. This region is typically exhibited by hydrocarbon fuels - negative temperature behavior - and it is important to describe it properly when making SI engine

\begin{tabular}{|c|c|c|}
\hline $1^{\text {st }}$ stage & $2^{\text {nd }}$ stage & $3^{\text {rd }}$ stage \\
\hline $\begin{array}{c}\text { Quasi-dimensional model }- \\
\text { OBEH code }\end{array}$ & $\begin{array}{c}\text { 1-D fluid dynamics model + FE solver } \\
\text { for engine part temperature - } \\
\text { GT-Power code }\end{array}$ & $\begin{array}{c}\text { CFD code + coupled chemical kinetics } \\
\text { solution - AMEM code }\end{array}$ \\
\hline Decoupled chemical kinetics solution - regression formulas (AE) to be used as \\
sub-models
\end{tabular}




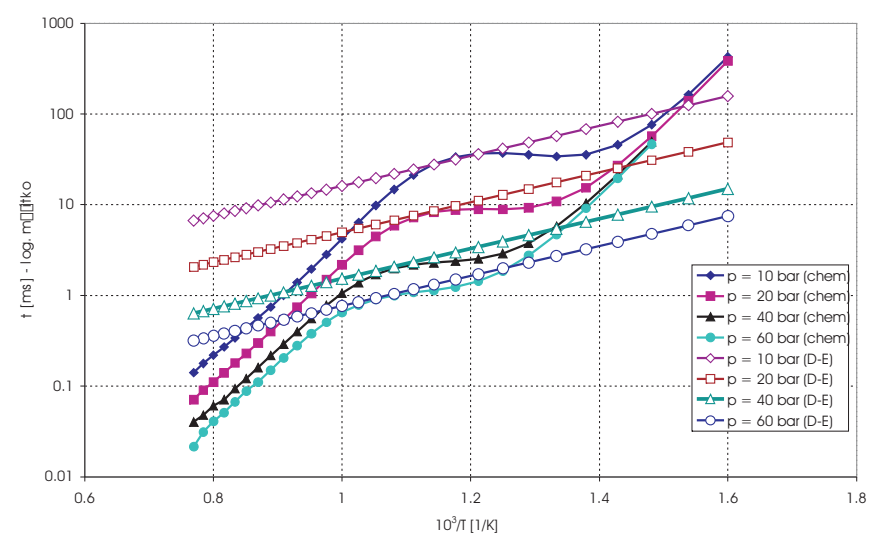

Fig. 3: Ignition delay time of isooctane. Comparison of detailed chemistry solution (chem) and empirical correlation of Douaud-Eyzat [7] (D-E)

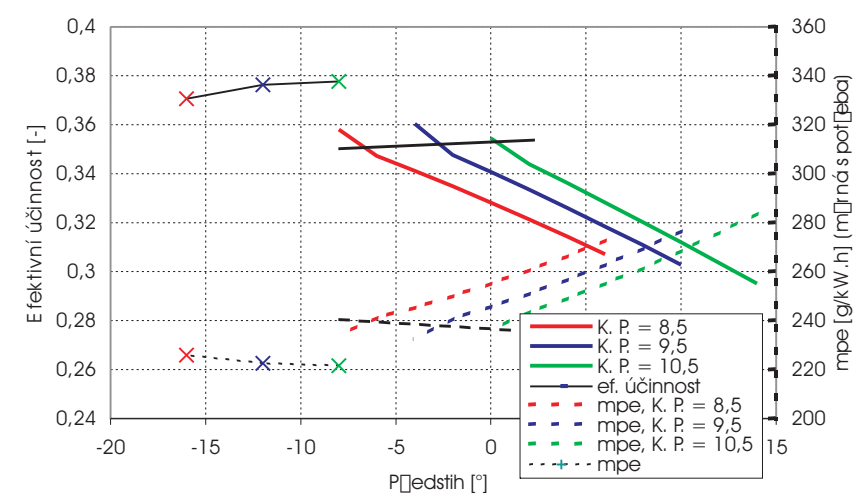

Fig. 4: SI Engine optimization. Engine efficiency and s.f.c. (mpe) as a function of spark advance and compression ratio (K.P.). Boost pressure of 1.5 Bar.

\section{alfa $7000 \mathrm{~W} / \mathrm{m} 2 \mathrm{~K}$}

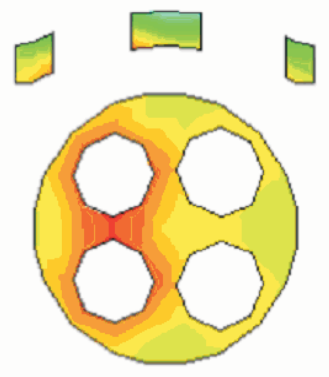

alfa $11000 \mathrm{~W} / \mathrm{m} 2 \mathrm{~K}$

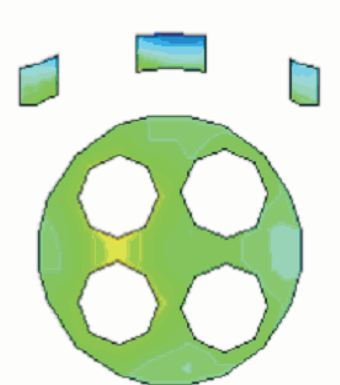

knock predictions. Typical results of SI engine optimization [8] - are shown in Fig. 4.

\section{Engine parameter tuning - wall heat transfer assessment}

In the next stage of engine development, a more sophisticated 1-D model together with the FE solver of the temperature field of the engine parts was employed $[9,10]$. The layout of this engine was the same, but the model accounts for the fluid dynamics in the pipes. The FE solver was used for a more detailed simulation of the influence of the cylinder wall temperature on knock induction. The solver was also used to evaluate the heat transfer to the cooling water [11]. This is very important precisely in the case of a highly turbocharged SI engine, because the high power density in the cylinder of the engine enhances the heat transfer to the walls and the cooling water. This leads to very hot regions on the cylinder liner/cooling water and the cylinder head/cooling water interfaces, which exhibit local boiling of the cooling water. The influence of the heat transfer coefficients is described in Fig. 5.

\section{Detailed in-cylinder phenomena solution - CFD model application}

The CFD model is the most advanced model in the simulation tool hierarchy. It is based on PDE and it treats time and space continuously. Such a model is usually limited to the simulation of an engine part, i.e., in-cylinder phenomena, etc., as it is very demanding. It can be combined with the previous models in order to determine initial and boundary conditions. In the work presented here, the Advanced Eulerian Multizone Model [12] developed by the authors was used to

alfa $9000 \mathrm{~W} / \mathrm{m} 2 \mathrm{~K}$

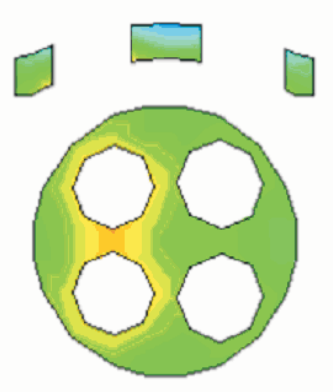

alfa $13000 \mathrm{~W} / \mathrm{m} 2 \mathrm{~K}$

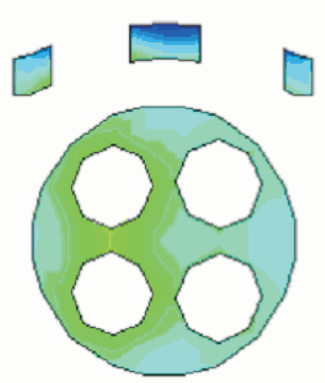

Fig. 5: Temperature field of the engine head for 4 different heat transfer coefficients (alfa) from head to cooling water. The heat transfer coefficient was chosen according to the heat flux density on the wall in an iterative procedure to ensure a realistic temperature drop on the wall 
simulate knock induction in a disc-shape cylinder. It requires the formulation of a very comprehensive model, including the chemistry. Unlike the previous models, the results of CFD simulations are not completely useable in the engine design procedure, but they are very useful as they give a deep insight into phenomena which are of concern. In the case presented here, the results show that knock occurs very close to the cylinder walls, which leads to a significant thermal load [12].

\section{Application of the CFD model to unconventional cycle simulation}

The simulation of an unconventional cycle by means of CFD simulation is a typical example of the use of an advanced method to estimate engine parameters and to propose an engine design. The AMEM code as adopted to simulate an IC engine with a porous medium (PM) taking place in the cylinder [13]. The purpose of the PM insert is to realize in-cylinder heat regeneration (ICR) in order to increase engine efficiency. The porous medium acts as a heat regenerator as it transfers energy to an instantaneous cycle from a the previous cycle. The energy supplied during the combustion may help to homogenize and stabilize the combustion. In addition, the "charging" of the regenerator restricts the temperature in the cylinder, preventing the formation of thermal $\mathrm{NO}_{x}$. As for the design of the heat regenerator, the authors considered a ceramic insert placed in a pre-chamber of a cylinder. The insert is made of SiC. A PM burner with high porosity $(0.9)$ is assumed in the presented simulations.

The PM burner concept has been used in steady state combustion systems, e.g., furnaces, boilers, with great success. However, the PM - IC engine simulation has to answer the question whether the concept provides all the advantages under unsteady conditions. Both engine efficiency and pollutant formation issues have to be considered. This explains why the CFD model should be used. Combustion in the new concept usually has to be modeled in a very complex way, employing chemical kinetics applied to a full reaction scheme

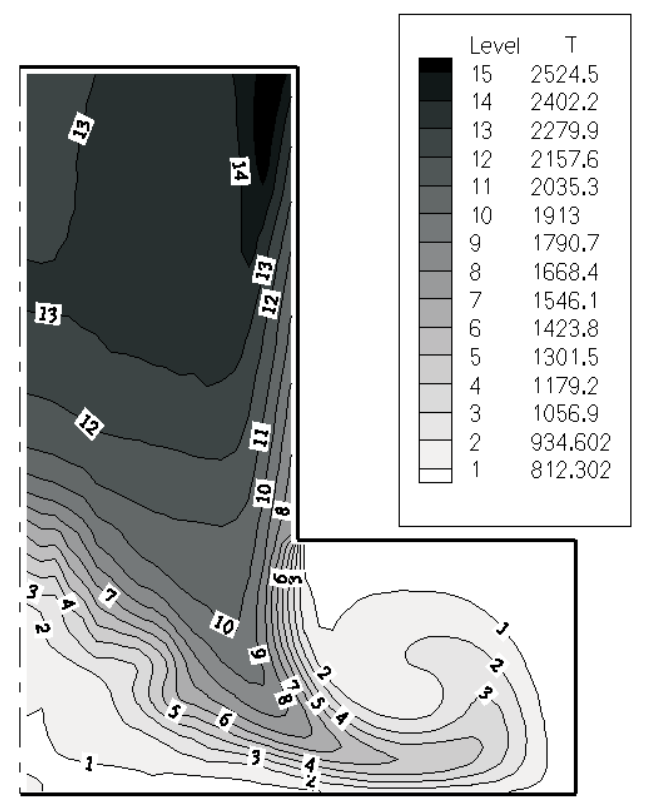

Fig. 6: Temperature field of the gas phase at the end of combustion 40 degCA after TDC

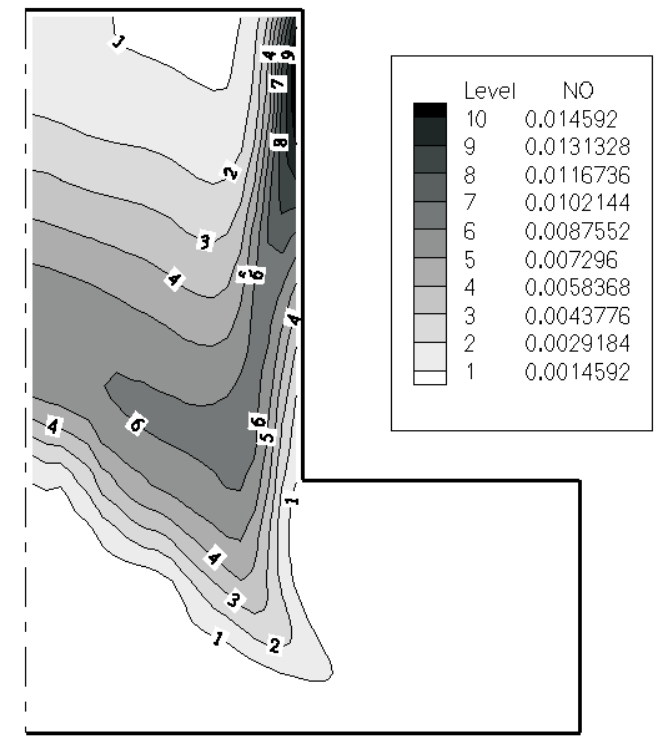

Fig. 7: NO mass fraction at 40 degCA after TDC. Hydrogen combustion. Chemistry model prediction.

of fuel oxidation. Examples of the results are shown in Fig. 6 and Fig. 7. The local temperature during combustion is unfavorably high - Fig. 6 - which enhances NO formation Fig. 7. The fuel is injected into the PM and the main part of the combustion occurs in the PM, which is inconvenient for the temperature. The combustion system only partially homogenize the temperature field during combustion. See [13] for a more detailed description of results.

The first simulations show that the PM concept needs to be further optimized. Despite the drawbacks of the CFD simulation, it provides significant advantages in the novel combustion system case, where there is a lack of experimental data. Moreover, some experimental techniques, e.g., PIV and LIF, cannot be employed because optical access to the PM is not possible.

\section{Conclusions}

This paper describes the main steps in inplementing of advanced models of the ICE system for preliminary optimization and design proposals. The current developments in engine structure caused by new fuels, materials and mechatronics approaches to control actuation are involved in it. This situation changes many old standard paradigms. On the other the model reacts adequately to ever increasing demands on efficiency and environmental impact of engine operation, manufacture and disposal. New thermodynamic procedures modularized according to the presented demands were described together with their hierarchy of precision (AE, ..., PDE). The use of precision levels should be relevant to the trade-off between predictable force, dependence on previous experience and requirements on detailed information.

The use of downsized engines may ensure better well-to-payload efficiency of a vehicle, thus reducing carbon dioxide and other emissions. The application of the different level models, and combination of them considerably enhance and accelerate the design process. The knock prediction capability is important mainly when proposing engine pa- 
rameters which cannot be easily changed for real engines, e.g., the compression ratio. The knock estimation procedure based on a combination of the chemistry and the Q-D zone model can be extended to new fuels. It adds predictive capabilities to the model.

The classical simple-to-advanced model hierarchy is advantageous in problems where either calibration of the model with experiments or current knowledge can be used to determine a model parameter. However, very advanced models based on PDE, e.g., CFD models have a great potential in problems where there is a lack of experimental data. In this case, such a model can be favorably employed in the first stage of the design procedure to explore this limits of a new concept. Moreover, the results of CFD computations can be generalized. This provides the basis for sub-model formulation to be used in simpler simulation tools.

\section{Acknowledgments}

This research has been supported by the Research Center project No. LN00B073 of the Ministry of Education of the Czech Republic. The support is gratefully acknowledged.

\section{References}

[1] Macek J., Valášek M.: "Initial Methodology for Concurrent Engineering”. In: Fiala P., Smrcek L. (eds.): Proc. of First International Conference on Advanced Engineering Design, CTU Prague, Prague 1999, p. 286-290, ISBN 80-01-02055-X.

[2] Macek J., Valášek M.: "Computer Aided Configuration Design of Internal Combustion Engines - CED System”. SAE Paper 2002-01-0903.. In: Modeling of SI Engines and Multi-Dimensional Engine Modeling. Warrendale, PA: Society of Automotive Engineers, 2002, Vol. 1, p. 225-241, ISBN 0-7680-0970-7.

[3] Macek J., Polášek M., Vítek O., Hvězda J.: “Comparison of Governing Equations for Lagrangian/Eulerian Approaches to Engine Modelling". Journal of KONES Internal Combustion Engines. Vol. 9 (2002), No. 1-2, p. 172-180, ISSN 1231-4005.

[4] Valášek M.: "Principles of Computer-Aided Systems Operation". In: Trappl R. (ed.): Cybernetics and Systems 88, Kluwer, Dordrecht 1988, p. 203-210.

[5] Livengood J. C., Wu P. C.: "Correlation of Autoignition Phenomenon in Internal Combustion Engines and Rapid Compression Machines". Proceedings of Fifth International Symposium on Combustion, Reinhold (1998), p. 347.

[6] Polášek M., Hofman K.: "Modelování detonací zážehových motorů". In: KoKa 2002. Račkova Dolina: SPU Nitra, 2002, Vol. 1, p. 59-66, ISBN 80-8069-051-0.

[7] Doaud A. M., Eyzat P.: Four-Octane-Number Method for Predicting the Anti-Knock Behavior of Fuels and Engines. SAE paper 780080, SAE Trans., Vol. 87 (1987).
[8] Hofman K.: "Vliv detonací na oběh zážehového motoru”. Diplomová práce U220.1, vedení Takáts M., Macek J., Polášek M., ČVUT FS, Praha: 2002.

[9] GT-Power, User's manual - Vers. 5.1. Gamma Technologies Inc., 601 Oakmont lane, Suite 220, Westmont, IL, USA.

[10] Vítek O., Polášek, M.: “Tuned Manifold System - Application of 1-D Pipe Model”. SAE Paper 2002-01-0004. In: Modeling of SI Engines and Multi-Dimensional Engine Modeling. Warrendale, PA : Society of Automotive Engineers, Vol. 1 (2002), p. 37-46, ISBN 0-7680-0970-7.

[11] Hlávka T.: "Studie přeplňování zážehového motoru". Diplomová práce U220.1, vedení Macek J., Polášek M., ČVUT FS, Praha: 2002.

[12] Polášek M., Macek J., Takáts M., Vítek, O.: “Application of Advanced Simulation Methods and their Combination with Experiments to Modeling of Hydrogen Fueled Engine Emission Potentials". SAE paper 2002-01-0373. In: Modeling of SI Engines and Multi-Dimensional Engine Modeling. SAE Congress 2002. Detroit: SAE. 2002. ISBN 0-7680-0970-7.

[13] Polášek M., Macek J.: "Homogenization of Combustion in Cylinder of CI Engine Using Porous Medium". SAE paper 2003-01-1085. In: Homogeneous Charge Compression Ignition (HCCI) Combustion. Warrendale, PA: Society of Automotive Engineers, Vol. 1 (2003), ISBN 0-7680-1165-5.

Ing. Miloš Polášek

phone: +420224352492

e-mail:polasekm@fsid.cvut.cz

Ing. Oldřich Vítek

phone: +420224352507

e-mail: oldrich.vitek@fs.cvut.cz

Prof. Ing. Jan Macek, DrSc.

phone: +420224352504

e-mail: jan.macek@fs.cvut.cz

Josef Bozek Research Center

Czech Technical University in Prague

Faculty of Mechanical Engineering

Technická 4

16607 Prague 6, Czech Republic

Prof. RNDr. Karel Kozel, DrSc.

phone: +420224357365

e-mail: karel.kozel@fs.cvut.cz

Department of Technical Mathematics

Czech Technical University in Prague

Faculty of Mechanical Engineering

Karlovo nám. 13

12135 Praha 2, Czech Republic 